from which organisms were identified in 202, of which two were fatal (see table). This is equivalent to a rate of 113 cases $/ 100000$ population/year. Although the majority of cases occurred in outbreaks, the majority of incidents were in families or sporadic cases. There is usually one case of salmonellosis under investigation in this borough.

The two general outbreaks were: (1) Salmonella newport in a mental handicap hospital (presumably) due to turkey; this outbreak involved two deaths. (2) $S$ bredenez in a primary school.

Failure by doctors to resort to bacteriology for undiagnosed diarrhoea meant that many cases of salmonellosis in the first outbreak were incorrectly diagnosed. Indeed none of 13 cases presenting to general practitioners were correctly diagnosed. This was particularly worrying as a number were food-handlers in the hospital concerned. This is not written in any spirit of criticism of colleagues, but rather to point out that the problem will not be solved by Government departments, regional epidemiologists, information systems, or committees, but by clinicians revealing the true extent of food poisoning by exploiting the laboratory service we already have.

J R WILKIE Medical Officer for Environmental Health
London Borough of Waltham Forest Langthorne Hospital, London E11

\section{Renal lesions in a case of septicaemia}

SIR,-The recent clinicopathological conference on a case of septicaemia (24 January, p 207) posed problems of interpretation both clinical and pathological which will have interested many readers. Our attention was drawn particularly to the findings in the kidneys, to the photomicrographs submitted, and to the observations made on the renal pathology found in this patient who died as a result of staphylococcal endocarditis and focal myocardial infarction.

We believe that the additional diagnosis of diffuse proliferative glomerulonephritis is poorly supported on the available evidence for the following reasons:

(1) The glomerular proliferation is minimal and where present is segmental. We accept that interpretation of photomicrographs is often difficult, but polymorphonuclear leucocytes are not conspicuous in the illustration (fig 8).

(2) Patent capillary loops are present (figs 8 and 9) and would seem to be much more numerous than one would expect in diffuse proliferative glomerulonephritis.

(3) The paucity of red blood cells in a necropsy specimen (noted by Dr M F Dixon) cannot in any circumstances be related to glomerular capillary circulation in life.

(4) In diffuse proliferation glomerulonephritis the mesangial thickening is more often centralstalk-derived rather than focal and peripheral as seen in the illustration, although the changes are minimal.

(5) An increase in endothelial cells does not particularly support the diagnosis since this is a non-specific reaction seen in the damaged glomerulus.

The present-day diagnosis of diffuse proliferative glomerulonephritis rests on the triad of light microscopy, electron microscopy, and immunofluorescence. Immunofluorescence is not reported in this case and there were no immune deposits visualised on electron microscopy. Such deposits might have been expected to be present in a case of diffuse proliferative glomerulonephritis of relatively short duration, as in this case, but they are often difficult to find.

We submit that the presence of diffuse proliferative glomerulonephritis is not substantiated by the arguments presented or the photomicrographs submitted. This would be a most unusual diagnosis in bacterial endocarditis and has infrequently been made since 1932. Since then the more likely condition has been recognised as focal endocapillary proliferative glomerulonephritis, which would seem to us to be the diagnosis in this patient.

Since the photomicrographs and diagnoses submitted in clinicopathological conferences are frequently regarded as authoritative, by medical students and practitioners alike, we suggest that in this case the alternative diagnosis of focal endocapillary proliferative glomerulonephritis might be considered and found more acceptable.

Trevor J Betteridge

RAF Institute of Pathology and
Tropical Medicine,

DAVID RAINFORD

Renal Unit,

Princess Mary's RAF Hospital,

RAF Halton,
Aylesbury, Bucks

Radiology and endoscopy in acute upper gastrointestinal bleeding

SIR,-The study reported by Dr G M Fraser and his colleagues (31 January, p 270) cannot be regarded as objective in that the authors simply took the case notes of patients admitted to various wards of the hospital in the years 1971-4, extracted what information they wished from endoscopy report sheets, and compared this with their own radiological findings in the same series of patients. They thus set themselves up as both prosecutors and jury.

An objective comparison of radiology and endoscopy in the context of a particular acute situation such as bleeding demands that both are carried out at an approximately similar duration of time from the commencement of bleeding and by endoscopists and radiologists of reasonably equal degrees of experience. It was only about the middle of 1974, however, that a policy of early endoscopy for alimentary bleeding came to be adopted in this hospital. This was the result of several reports in 1972 and 1973 which suggested the advantages of it. During the period of Dr Fraser's study (19714) patients with upper gastrointestinal haemorrhage were frequently endoscoped by junior members of the staff whose opinions could not necessarily be equated with the radiological opinions of such highly experienced consultants as Dr Fraser and Dr Cummack. Furthermore, all but a few patients with upper alimentary bleeding were admitted to wards other than those of the gastrointestinal unit and in those years the requests for endoscopy were more commonly made more than 48 hours after admission.

In the series reported there were 70 patients who had radiology within 48 hours of the haemorrhage and only 27 who were endoscoped within this period. Of the 70 , the radiological diagnosis was positive in 44 instances and of the 27 , the endoscopic diagnosis was positive in 15 instances. There is no statistical significance in the difference between these results. Since the policy of early endoscopy was estab- lished in 1974 the high degree of diagnostic accuracy reported by others has been confirmed by our experience.

The communication of Dr Fraser and his colleagues simply demonstrates that two senior radiologists have a high standard of diagnostic accuracy but not more so within the first 48 hours of an upper alimentary haemorrhage than that achieved by half a dozen endoscopists of widely varying experience and before the establishment of the policy of early endoscopy. Their conclusion that radiology as well as endoscopy has a place in the diagnosis of upper alimentary haemorrhage is not disputed, but the size of this is probably better assessed in the prospective study of McGinn et $a l^{1}$ mentioned in the discussion.

University Gastrointestinal Unit,

W SIRCUS

Western General Hospita
Edinburgh

${ }^{1}$ McGinn, F P, et al, Gut, 1975, 707.

SIR,-Fibreoptic endoscopy has made a substantial contribution to the management of acute gastrointestinal haemorrhage. Numerous studies have investigated its contribution and we are now at the stage where carefully planned prospective studies are required and are indeed in progress. I was therefore disappointed to read the recent article by $\mathrm{Dr} G \mathrm{G}$ Fraser and others (31 January, p 270), whose paper does neither radiology nor endoscopy justice. They compare radiology and endoscopy in acute upper gastrointestinal bleeding and have the temerity to publish their results when only $61(55 \%)$ of their 112 patients had both examinations. Endoscopy was performed on only $64 \%$. Their finding that endoscopy diagnosed only $57 \%$ of cases is greatly at variance from other papers which they quotegiving figures ranging from 76 to $97 \%$ accurately diagnosed. I suggest that little weight can be put on their findings since in no way was this a controlled trial, only half the patients had both examinations, and a smaller proportion still were operated upon to confirm the final diagnosis.

Endoscopists welcome careful studies. We feel that the technique contributes greatly to the management of such patients but we have now got beyond the stage where inadequate data should be published. We trust that in future, Sir, only more careful studies will appear in your pages.

D G ColiN-JoNES
Hon Secretary,
British Society for Digestive Endoscopy

Queen Alexandra Hospital,

Cosham,
Portsmouth, Hants

\section{Trial by traction}

SIR,-Ever since traction for lumbar disc lesions was put forward 26 years ago $^{1}$ uncertainty has continued on indications and technique. Yet the matter is perfectly simple. Just as manipulation affords the appropriate treatment for a small cartilaginous (hard) displacement, so is traction called for in a small nuclear (soft) protrusion. The former is clicked back (usually, alas, by some layman); the latter is sucked back more gradually. Treatment depends on the size and consistency of the lesion. Radiography has shown that it takes two minutes' sustained stretch before the 
intervertebral joint space widens. Hence intermittent or pulsating traction acts merely on muscles, evoking the stretch reflex but not the suction that determines the effect on the protrusion.

The absolute contraindication to traction is acute lumbago. ${ }^{2}$ Though pain and signs cease while the pull is maintained, the slightest diminution in tension causes such agonising twinges that it takes several hours to get the patient off the couch, and some aggravation lasts several days. I have also emphasised in succeeding editions of my book that traction is valueless (though not harmful, as in acute lumbago) in sciatica with neurological deficit. Impaired conduction shows that the bulge has become larger than the aperture whence it emerged; reduction by manipulation or traction is now impossible. This view was corroborated by a controlled trial in Norway. ${ }^{3}$ As for the "nipped synovial fringe" dear to those who attribute back troubles to disorders of the facet joints, the plain fact is that synovial membrane is devoid of nerves and pain cannot arise from it.

By all means let us have trials, as $\mathrm{Dr} B \mathrm{O}$ Scott suggests (31 January, p 284), but let them be designed to establish new facts or to investigate findings as yet uncorroborated.

\section{London W1}

JAMEs CyriaX

1 Cyriax, J H, British Medical fournal, 1950, 2, 1436. p 450 . London, Baillière Tindall 1954

p 450. London, Bailliere Tindall, 1954.
Weber, H, fournal of the Oslo City Hospitals, 1973, 23,
167.

\section{Cancer statistics}

SIR,-May I reply to some of the criticisms made by Professor $M R$ Alderson and by Dr L J Kinlen and Professor M P Vessey (31 January, p 280) concerning my recent paper (10 January, p 86).

Professor Alderson ${ }^{1}$ has discussed some of the problems of medical information systems, but many difficulties still remain. Any alteration in a national registration system, whether it be for cancer or motor vehicle licences, involves a great deal of work which can be justified only if the result promises to be worth while. Collection of detailed data from original case notes is not impossible and is achieved at some large hospitals such as the Royal Marsden Hospital and Institute of Cancer Research, London, and the Christie Hospital and Holt Radium Institute, Manchester. The difficulties are then those of data abstraction, storage, and retrieval. Regional registries often lack staff to perform any but the most immediate tasks; they do not lack enthusiasm.

Both Professor Alderson and Dr Kinlen and Professor Vessey imply that I had either overlooked or minimised the value of epidemiological studies compared with that of survival rate investigations. I can only reply that perhaps a better title for my paper would have been "Cancer treatment statistics," since it was with this topic only that I was concerned in that communication. Indeed, I have recently used registry data for an epidemiological study of incident age distribution for cancer of the cervix in England and Wales, $1945-69^{2}$, and I am also well aware of the excellent epidemiological work which is produced by Professor Doll's departments in Oxford.
In reply to $\mathrm{Mr} F \mathrm{E}$ Whitehead (24 January, p 223) concerning $\mathrm{SH} 3$ returns I would like to make three points. (1) Consultation statistics (part 2, line 18) and treatment statistics (part 3 , line E) are given for both new outpatients (that is, numbers of persons) and outpatient attendances (that is, numbers of visits). This makes a total of four radiotherapy outpatient statistics on each $\mathrm{SH} 3$ return, in addition to any inpatient statistics. (2) My communication referred only to numbers of new outpatients, whereas $\mathrm{Mr}$ Whitehead's comments were mainly based on information relevant to outpatient attendances. I would agree that attendance figures in parts 2 and 3 will almost inevitably differ, but this is not the point in question. Although the first attendance of a cancer outpatient in a radiotherapy department may be for treatment, the need having been confirmed elsewhere, by the nature of most treatment schedules the patient will be attending for treatment over a period of weeks, and consultation with the medical staff of the radiotherapy department is normally bound to occur. In this case the patient will count once as a new outpatient in part 2 of $\mathrm{SH} 3$, since he will receive a series of consultation attendances, and will also count once as a new outpatient in part 3 of $\mathrm{SH} 3$, because he is attending a number of times for treatment. (3) $\mathrm{Mr}$ Whitehead refers to both radiology and radiotherapy departments, although only radiotherapy statistics are under discussion.

\section{Westminster Medical School,
London, SW 1}

R F MOULD

Alderson, M R, in Central Government Review Health Statistics, Vol 2, Review of UK Statistical Sources, ed W F Maunder. London, Heinemann, 1974.

Mould, R F, fournal of Obstetrics and Gynaecology of the British Commonwealth, 1974, 81, 644.

\section{Changing patterns of cancer}

SIR,-Perhaps the most interesting observation in the changing pattern of bronchial carcinoma (leading article, 7 February, p 301) is a fall in the incidence of the disease in the younger age groups in both sexes. The rates started to fall in men up to the age of 49 in 1950 and it fell steadily between 1969 and 1972 in women under the age of 45.1

Is it certain that this fall is entirely due to changing smoking habits? The men reached their present level of consumption in 1940 , and their annual consumption per head over the age of 15 has remained reasonably steady since then at just under 4000 cigarettes per year; the consumption amongst the women is still rising and reached 2560 by the end of $1972 .{ }^{2}$ If a comparison is made between the average consumption among women who reached 45 ten years ago and those now reaching that age it can be shown that the latter had substantially higher cigarette consumption per head than that of their elder sisters, the difference being in the order of $3: 2$, but they have a falling incidence of bronchial carcinoma. Surely there must be another factor at work.

J R BELCHER

The London Chest Hospital,

\section{London E2}

1 Office of Population Censuses and Surveys, Registrar General's Statistical Review of England and Wales,

Todd, G F, Changes in Smoking Habits in the UK, Tobacco Research Coun

\section{Nucleus hospitals}

SIR,-Your leading article (31 January, p 245) criticises the concept of nucleus hospitals, suggesting that community hospitals are going to be unable to act as supporting units. You cannot seriously suggest that "all patients admitted on medical grounds to hospital nowadays require the kind of support from laboratory and technical services that can best be provided in one large unit rather than half a dozen small ones." I presume that the urban counterpart of those patients cared for in existing rural community hospitals are being admitted to the medical wards of urban district general hospitals. Do they really need such sophisticated technological support? To suggest this suggests that a considerable number of patients are receiving second-class hospital care.

I agree that effective community hospitals need rehabilitation services and good domicilary community care. Savings on large district general hospitals that may now not be built should go some way towards providing these.

Tewkesbury, Glos

A J Chapman

\section{Psychiatric aspects of shoplifting}

SIR,-I am prompted by Dr J Todd's communication "Pharmacogenic shoplifting ?" (17 January, p 150) to advance some impressions regarding shoplifting.

The practitioner, perhaps helpfully prompted by and widely seeking information from relatives or other workers, can usefully bear in mind possible contributory or explanatory factors, including the following: (1) The pharmacogenic factors mentioned, adding also the "hang-over" effect of night sedation (and indeed the disorganising effect of insomnia itself), the possible side effects of antiepileptic, steroid, or antihistamine therapy, and the confused phases during electric convulsion therapy. (2) Schizophrenic patients-some florid but others offending while being vague or deluded. (3) Depressive states, in which some endogenous cases may well reflect a deliberate desire to be caught-that is, a suicidal equivalent or appeal for help-and other reactive cases with the inattentive patient preoccupied with problems or distress-for example, cases of recent bereavement. (4) Anxiety states with significantly impaired concentration as one aspect of reduced ability to cope normally. (5) Mentally handicapped individuals in whom the lure of glitter and possession is greater than their sadly illdeveloped sense of right and wrong. (6) Organic cases with distraction through physical illness-for example, orthopaedic, neurological, gynaecological, or endocrine, with discomfort and diminished physical skill, or intracranial lesions, head injury, or most frequently, a dementia or pseudodementia with genuine confusion and impairment of memory. (7) An abnormal distracting influence-for example, trying to shop and cope with mentally handicapped or hyperkinetic youngsters. (8) The stress of crowded, bustling, noisy stores compelling the sensitive or claustrophobic patient to "escape," forgetting to pay. (9) Often the combination of several of the above factors which, when considered together, could reasonably constitute "a lack of intent." And finally (10) 